\title{
EVIDENCE-BASED HEALTH PROMOTION FOR YOUTH, FARMERS AND FAMILIES OF THE GORE COMMUNITY: A FOCUS ON MENTAL HEALTH AND FAMILY VIOLENCE
}

\author{
Aleisha Ferris, Anja Koehler, Anna Drummond,Anna Power, \\ Ben Rowley, Brianna Atkins, Cassie Davies, Catherine Huggins, \\ Danielle Martin, Danni Ma and Jean Ross
}

\begin{abstract}
INTRODUCTION
Community health nursing takes a population-based view of health and well-being, viewing the entire community as a client (Francis, Chapman, Hoare, \& Birks, 2013). To promote the health of a community is to empower the community both as a group and as individuals so that they have more control over, and improve, their health status (Patterson, 2007). This community health project involved a nursing assessment of the Gore community in Southland, New Zealand. Youth mental health, family violence and mental health in farmers were identified as specific health issues in the community. Following a review of evidence from the literature, health promotion resources were developed to target these health needs. An impact assessment of the project was carried out three months later, and evidence was found showing positive health and social impacts on Gore and the wider rural community.
\end{abstract}

\section{ETHICS APPROVAL}

Category B ethical approval was granted through the Otago Polytechnic School of Nursing Ethics Committee for this project, and Māori representatives of the Otago Polytechnic Kaitohutohu Office were consulted throughout the process.

\section{GORE}

Gore district is situated on the plains of the Southland region between Dunedin and Invercargill. It covers an area of $125 \mathrm{l} \mathrm{km} 2$ and is divided into four electoral wards: Gore, Mataura,Waikaka and Waimumu/Kaiwera (Gore District Council, 20I3a). The community health assessment focused on the Gore ward, comprising a town situated in the centre of Gore district surrounded by agricultural land.

\section{Community profile}

The population of the Gore district is 12,033; 91 percent identify as European and II percent as Māori (Statistics New Zealand, 2013). Historically, the area was an important transit route for Māori, with the Mataura River being a significant food source (Beattie, 1962). European settlement from 1855, followed by the goldrush boom of the 


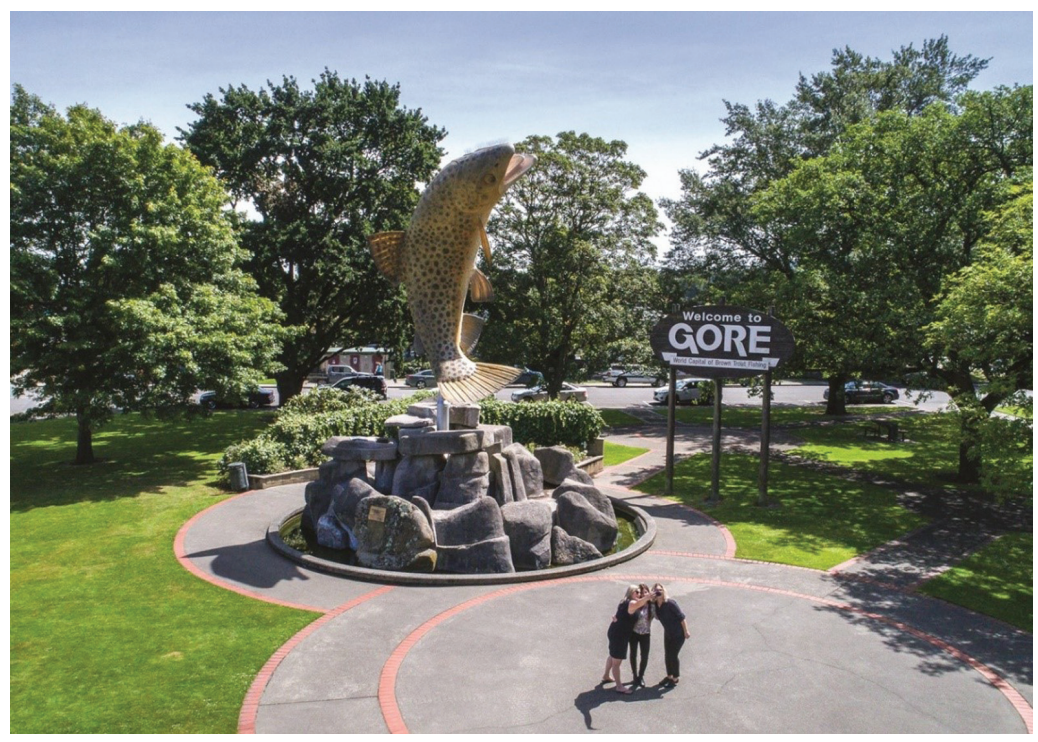

Figure I. Gore's "brown trout fishing capital of the world" statue. Source: Gore District Council.

1860s, saw significant growth in the town of Gore, which continued to prosper until a downturn in agricultural production in the 1970s (Grant, 2008). In recent years, as Gore's working population moves towards retirement and the population is declining due to urban drift, concerns have been raised over the need to encourage growth in the district (Kelly, 20 16; Newman, 20 8).

Gore is a tight-knit, supportive rural community with evident pride in the town's heritage and a proactive approach to future planning. Farming is a major influence on the community's character, bringing with it a self-reliant attitude and a strong work ethic. The Gore District Council (20 I3b) describes the town's lifestyle as "rural city living," having the cultural and sporting advantages of a city and the values and benefits of rural living. These values are described by the council as an energetic and positive attitude, politeness, helpfulness, friendliness, transparency and consistency.

\section{Health needs}

The Gore community is well-resourced in terms of health and social services. Despite this, our contact with representatives of these services identified a lack of youth mental health services within the community and a high prevalence of youth depression, anxiety and suicidality. Representatives of the education sector suggested that a lack of resilience in young people contributes to these mental health issues (Local professional, personal communication, April 3, 2019). The mental health of dairy farm labourers in the rural community was also raised as a concern as a result of their social isolation, lack of support and the "tough southern man" culture, which acts as a barrier to seeking help (Local professional, personal communication, April 3, 2019). Social and justice service representatives identified family violence as a significant threat to community well-being, with approximately 80 percent of all police callouts being family violence-related. The local women's refuge had received 350 presentations by people seeking help with family violence issues over the previous year (Local professional, personal communication, April 3, 20 I9).

Health promotion resources were developed to target these various health needs using the Ottawa Charter (World Health Organization, 1986) as a framework to enable people to have control over and improve their health. The following report provides an overview of the literature findings and the development of health promotion resources for youth mental health, family violence and farmer's mental health in Gore. 


\section{HEALTH NEED:YOUTH MENTAL HEALTH}

Resilience in early adolescence and its impact on youth mental health and behaviour: Development of a health promotion resource for the youth of Gore

\section{Introduction}

The period from early childhood to adulthood is full of physical, social and emotional changes as well as unforeseen challenges and stressors. Without the ability to deal with these developments, such adjustments and confrontations can lead to negative youth mental health outcomes and anti-social behaviours such as substance abuse and gang involvement (Harris et al., 20।5).

In Southland, 16.6 percent of youth identify as being depressed, and 19.2 percent experience mood or anxiety disorders (New Zealand Health Survey, 2018). According to a representative from Oranga Tamariki Gore, there has been an increase in presentations of youth experiencing mental health issues and associating with drugs, alcohol and gangs as a coping mechanism. According to Oranga Tamariki, this rise in youth mental health issues can be related to individuals' past traumatic experiences and their inability to cope with them in a healthy manner (Local professional, personal communication, April 3, 2019). Teachers spoken to within the Gore community reported that a significant proportion of children lacked resilience and experienced mental distress (Local professional, personal communication, April 3, 2019).

The Adolescent Health Research Group (2013) has identified an inability and resistance by youth to seek help when faced with distressing situations. While seeking help is a crucial skill and resource associated with resilience, only 22.2 percent of southern adolescents seek help with their emotional difficulties (Southern District Health Board, 2016). This suggests that many youth lack the ability and knowledge to overcome obstacles in a positive way. Furthermore, the Southern District, including Gore, lacks sufficient youth mental health services, making access to such services difficult (Southern District Health Board, 2016).

Adverse mental health outcomes in youth can thus potentially be credited to a lack of resilience developed in adolescence. Gluckman (2017) supports this analysis by acknowledging that the progression of youth mental health distresses and disorders is often linked to an underlying lack of resilience in the face of stressors or traumatic events. A person's youth mental health status often progresses into adulthood, which presents its own problems in the community. Mental illness during youth may result in individuals who lack the competencies necessary for typical social and educational attainment, which may in turn negatively influence their adult life, resulting in continuing mental health and social issues (Wickrama, Conger, \& Abraham, 2005).

In Gore, there are limited mental health and addiction services available to cope with youth who are experiencing these illnesses and social disadvantages. The ward's limited services are not equipped to help these young people once they reach adulthood and continue to suffer with mental illness and anti-social behaviours. Health promotion resources addressing resilience which are targeted at adolescents may help to break the cycle of psychological distress extending from youth into adulthood.

\section{Literature review}

There is a wealth of evidence-based literature that supports and recognises the potential for resilience-building activities in early adolescence with a view to decreasing negative mental health outcomes and anti-social behaviours in youth. Resilience is defined as the capacity to adapt to, overcome and manage stress and adversity (Lown, Lewith, Simon, \& Peters, 20I5). In relation to mental health, adolescents who develop resilience are able to cope with stress in a positive manner and are less likely to develop unhealthy social behaviours in their youth as a coping mechanism (Murphey, Barry, \& Vaughn, 20I3). Furthermore, Lee, Cheung and Kwong (2012) report that building resilience 
at a young age is a major contributing factor to positive youth development, accompanied by enhanced skills in conflict resolution and problem solving and greater optimism. Such characteristics provide youth with the ability to overcome stressors in a positive manner, and not conform to anti-social behaviours. Conversely, a lack of resilience in youth has been associated with outcomes such as crime, poor educational performance and involvement in risky behaviours, which all contribute to poor mental health (Khanlou \& Wray, 20I4). These findings underline the importance of building early resilience strategies for youth in schools. It is also important to consider which age group should be targeted for the best outcomes and what activities are the most beneficial for the development of resilience.

When implementing resilience-building strategies, it is important to recognise the appropriate age to intervene in order to maximise the positive outcomes and benefits to youth mental health. Youth and early adulthood have been identified as the prime age group for the onset for mental health issues which, if left untreated, will carry on into adulthood (Zarobe \& Bungay, 20 17). Kessler et al. (2007) reviewed the literature on the most at-risk age group for the onset for mental disorders, concluding that almost half of all lifetime mental illnesses start in the mid-teens. Since the majority of mental health and substance abuse disorders begin during youth and early adulthood, investing in developing resilience early in the life course is a powerful health-promoting step with lifelong benefits (Khanlou \& Wray, 2014).This evidence provided the rationale for directing the group's health promotion resources focusing on resilience towards children in early adolescence ( $10-14$ years), with a view to preventing and minimising the negative health and social outcomes associated with youth (15-24 years) in the Gore community.

In order to develop resilience in early adolescence, an understanding of the most effective strategies and activities is important. Research reviewed by Condly (2006) has shown that extracurricular activities such as sport and art can have a positive effect on building resilience in schoolchildren. Involvement in extracurricular activities has been shown to increase student motivation and positive connections with the school, which in turn lessen anti-social behaviour and delinquency (Condly, 2006). Extracurricular activities are an excellent way to develop social and conflict resolution skills, which are not always available in the classroom (Downey, 2008).

According to Steiner, McQuivey, Pavelski, Pitts and Kraemer (2000), adolescents who played sport reported fewer mental health problems, indicating that participation in extracurricular sporting activities can contribute positively to mental, as well as physical, health. Participation in sport in early adolescence introduces young people to moral norms and values such as fairness and justice, which in turn encourages pro-social behaviours and reduces risky behaviours later in life (Johnson, 20I5). Hall (20II) conducted a study into the connection between sport participation and overall perceived resilience in youth. He reported that participation in sport increased self-confidence and the ability to overcome setbacks. He concluded that these skills and learned resilience were transferable to individuals' everyday lives and protected against negative youth mental health outcomes and involvement in antisocial behaviours.

Art as a form of extracurricular activity includes dancing, singing, drama and visual arts, and has also been linked to the development of resilience in adolescence. Zarobe and Bungay (2017) found that participating in arts activities had a positive effect on self-confidence, self-esteem and relationship-building and encouraged a sense of belonging. These features are associated with the development of resilience, positive mental health and positive social behaviours. Art encourages critical and creative thinking and gives opportunities to freely express one's inner self, transforming internal struggles into an art form. Group art programmes in schools could potentially offer early adolescents a valuable form of support and enhance their ability to develop into well-rounded individuals, effectively functioning as a preventative service (Cohlic, Eys, \& Lougheed, 20 I I).

\section{Health promotion resources:Written submission and poster}

The literature reveals that extracurricular activities such as sport and the arts can teach resilience during early adolescence by focusing on students' strengths and building self-esteem. Schools can potentially play an important role in this process by encouraging student participation in these activities. 
The local research undertaken by the group revealed that sporting and art facilities are largely accessible to adolescents in Gore. As a result, a written submission was prepared as part of this community health project and sent to the Gore District Council; it recommended the implementation of annual sport and art days in the community as a way of introducing these activities to local children and promoting their engagement in them.

In addition, a poster was developed as a health promotion resource for schools with the aim of encouraging children to recognise and acknowledge their feelings and experiences (Figures 2 and 3). It promotes the 'bounce back' strategy developed by Noble and McGrath (2005), which gives tips on how to overcome difficult experiences. The poster also included a list of IT applications and phonelines as a way of introducing external support services to the children. The poster is interactive and allows children to write their own list of who they can talk to, as well as list their personal strengths, with the aim of building positive self-esteem, a key element of resilience.

\section{Impact assessment}

A follow-up discussion with the Gore District Council regarding our written submission was positive, with a representative suggesting that the health promotion resources may be a valuable component of future strategies in the community. The principal of a local school where the posters were distributed described them as having an immediate and ongoing positive impact for both students and teaching staff. Children were engaging in the flow chart and teachers were using the resource to provide additional support to students, as well as refer any identified issues to the principal. The principal anticipated that the health promotion resource would be particularly useful in assisting children through transitional phases of their life such as changing schools or year levels. These responses provide evidence of the project's positive impact in building resilience and improving mental health outcomes for the youth of Gore.

\section{Tips on how to Rounce Brack:}

Bad times don't last, and things get better.

(1) ther people can only help if you share with them.

$\bigcup_{\text {nhelpful thinking only makes you feel worse. }}$

Wobody is perfect - not you. not your friends, not your family. not anybody!

Soncentrate on the good things in life. no matter how small.

Everybody suffers, everybody feels pain and experiences

- setbacks; they are a normal part of life.

Blame fairly - negative events are often a combination of things you did, things others did, and plain bad luck.

ind ccept what you can't change and try to change what you can.

@

atastrophizing makes things worse - don't fall prey to believing in the worst interpretation.

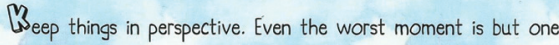
moment in life.

Figure 2. "Bounce back" acronym poster. Source: Noble and McGrath (2005).

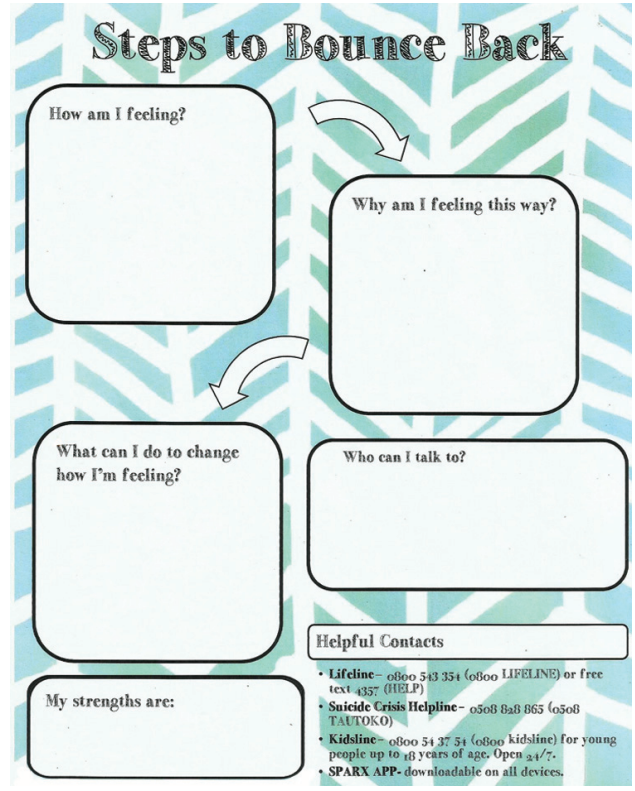

Figure 3. Steps to "Bounce back" interactive poster. Source:The authors. 


\title{
HEALTH NEED: FARMERS' MENTAL HEALTH
}

\author{
Promoting farmer's mental health in Gore \\ through support of healthy social interaction
}

\section{Introduction}

A high incidence of mental illness and suicide are significant health issues for male farmers worldwide (Roy,Tremblay, Oliffe, Jbilou, \& Robertson, 2013). Gore is no exception to this trend, as highlighted by suicide rates among young farmers in the community (Local professional, personal communication, April II, 2019). Farmers are exposed to risk factors such as environmental impacts, isolation and high levels of stress, as well as stigmas related to traditional understandings of masculinity. A review of the literature revealed the dominant contributing factors to mental illness in young farmers, which established an evidence base for development of a health promotion resource to address mental health issues among farmers in Gore.

\section{Factors contributing to mental illness in farmers}

\section{Adverse environmental conditions}

Southland experiences less average sunshine hours and colder temperatures than the rest of New Zealand (Macara, 20 13).A lack of sun exposure can contribute to depression due to reduced vitamin D synthesis (Farrington \& Moller, 20 I3). Therefore, farmers in Gore are at a greater risk of vitamin D deficiency, which may impact on their mental health. Lack of sun exposure can also result in reduced production of the mood-boosting hormone serotonin, which is associated with a type of winter depression known as seasonal affective disorder (Nicol-Williams, 2018).

\section{Isolation}

Isolation is another factor which may contribute to mental illness among farm workers (Fraser et al., 2005). Agriculture is at the forefront of Gore's economy, and farmers make up a large proportion of the community (Gore District Council, 2019). The physical isolation of these farmers affects their mental health in numerous ways including limited access to healthcare services due to distance, inadequate transport and long working hours. As a result of these factors, it is suggested that farmers' mental health can deteriorate slowly and thus avoid being detected (Fraser et al., 2005).

Social isolation also affects farmers' mental health, as there are limited opportunities to express concerns and make connections with others. According to Kawachi and Berkman (200 I), being socially connected is psychologically beneficial, while a lack of social networks and a minimal number of close relationships are associated with depressive symptoms. Personal isolation can occur when farm workers live alone. Gregoire (2002) found that a protective factor for men's mental health is being married or having a person they trust living at home. Having someone readily accessible to talk to can reduce the risk of developing a mental health problem. However, the research suggests that rural men can be unwilling to express their emotions due to cultural barriers (Macdonald, 20 17).

\section{Attitudes and the masculinity stigma}

Getting support in rural communities can be difficult, particularly as support providers may be under-resourced and not easily accessible to isolated farm workers. This can escalate potential problems as, without an outlet, problems can escalate and become highly stressful (Health Promotion Agency, 20 I8). Because of this situation, it is all the more important to understand the positive consequences of sharing and expressing personal concerns. In New Zealand, and particularly in Southland, among many men there is a stigma associated with sharing thoughts and feelings, which is considered to be a weakness (Macdonald, 2017). As a result of this attitude, many rural men contain their thoughts and troubles, leading to an increase in anxiety and depression. Mackenzie, Gekoski and Knox (2007) found 
that men were less open than women in acknowledging mental health problems and seeking professional help. Such findings are concerning and raise the question of how males can be encouraged to discuss and prioritise their own mental health.

Fear of stigmatisation is a significant barrier to people seeking help or speaking out (Corrigan, 2004). It diminishes self-esteem and reduces opportunities for social interaction (Hammer \& Vogel, 20 I0). In a small community such as Gore, stigma can be heightened due to the concern that personal information can easily be shared and become known to everyone. For rural males living in the Southern region of New Zealand, there has traditionally been an expectation to portray the 'Southern Man' persona - an individual who is strong-minded, tough and capable (Jackson, Gee, \& Scherer, 2009). The Southern Man portrays an older ideal of masculinity in which men must play sport, never drink cocktails, keep animals solely for work purposes and never share their thoughts and emotions (Jackson et al., 2009).

Our research therefore suggested that health promotion should be focused on challenging these attitudes, but also integrating them with alternative ideas which are relevant and acceptable to men. The aim was not to change rural men's attitudes to life, but to create an alternative pathway that would enhance their mental health.

\section{Social interaction and talking therapy}

The literature suggests that, historically, beer has been an essential aspect of manhood in the Western world (Strate, 1992). Together with sport, beer-drinking has traditionally been the Southern Man's means of social interaction (Jackson et al., 2009). Engaging in social activity and maintaining social connections are important factors in maintaining psychological well-being (Kawachi \& Berkman, 200I). We became aware that health promotion initiatives could incorporate these beneficial elements to help lower the incidence of mental illness and its associated stigma within the rural community of Gore, and to promote awareness and participation in self-care practices (Corrigan, 2004).

A current non-pharmacological intervention for mental illness is a process known as cognitive behavioural therapy (CBT). CBT is a talking therapy which engages the client's cognition in order to help change their attitudes and behaviours (Blenkiron, 20I5). This therapy utilises the idea that cognition influences how people think, feel and behave. If people are able to change their cognitive processes through talk therapy, it can change how they see the world (Dozois, Dobson, \& Rnic, 2019). Therapies such as CBT utilise the power of communication and the productiveness that accrues from engaging with others, strategies which may be useful for the male farmers of Gore.

\section{Health promotion resource:The drink cooler}

The literature suggests the need for male farmers to open up and engage in healthy conversations about how they feel and what is happening in their lives. Creating a health promotion resource which encourages rural Kiwi men, such as those in Gore, to be more open to conversation may begin to relieve stress, build camaraderie and reduce the impact of the talking stigma on farmers' mental health (World Health Organization, 1986).

A drink cooler with health promotion messages targeted at male farmers was therefore developed as part of our community health project (Figures 4 and 5). The phrase "crack open a cold one and crack on with the conversation" is printed on the side of the cooler to suggest that sharing a drink with mates is an opportunity to have a healthy conversation, thus challenging the stigma around opening up. The aim is to make having a drink a social lubricant for male farmers in order to reduce stigmatisation and improve their mental health. This small keepsake is not only practical but can also be the icebreaker they need to "crack on" with their conversation. Phone numbers of existing help lines are printed on the drink cooler to refer users to available support services. 


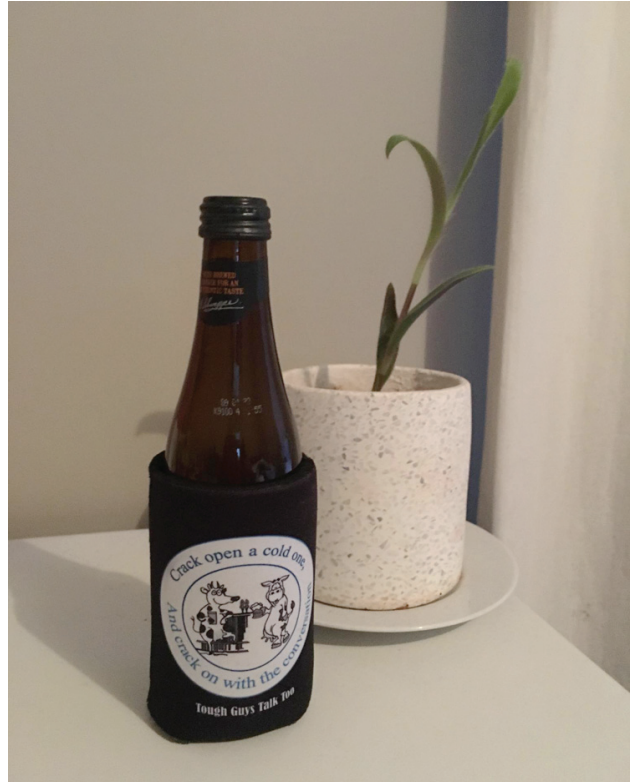

Figure 4. Drink cooler (front). Source:The authors.

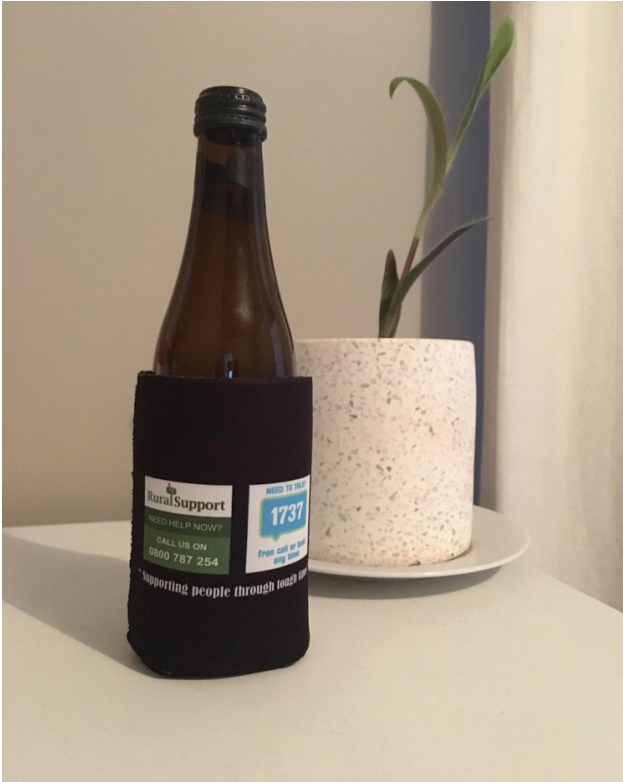

Figure 5. Drink cooler (back).

Source:The authors.

\section{Impact assessment}

After producing 12 prototypes, which were placed in stores in the Gore community, contact was made by the founder of Will to Live, a mental health campaign for young men, who requested 200 additional coolers for the Balclutha section of the nationwide mental health forum. Three members of the project group travelled to this forum, where the project was acknowledged, and the drink coolers were very well received by attendees. A further order of 1000 was made to be distributed in future events across the nation. The social impact of this resource is ongoing and is reaching more and more communities. This is evidence of its potential to raise awareness and encourage healthy conversations with the aim of improving the health and wellbeing of individuals and communities.

\section{HEALTH NEED: FAMILY VIOLENCE}

Family violence prevention from a male perspective: development of health promotion resources for the community of Gore

\section{Introduction}

The New Zealand Ministry of Justice (2019) defines family violence as "physical, sexual or psychological abuse against any person by someone with whom they have a close personal relationship. Psychological abuse includes economic and financial abuse, threats of violence, property damage and causing children to witness violence. Family violence includes intimate partner violence, elder abuse and neglect, abuse of a family member with disabilities and child abuse and neglect" (p. I).

Family violence has been recognised as a health issue due to both the immediate and long-lasting harm it causes to individuals, families and communities (Ministry of Health, 2016). Among the health consequences to individuals described by the World Health Organization are acute physical injuries, chronic conditions, sexual and reproductive disorders, behavioural disorders, mental illness and death (Krug, Dahlberg, Mercy, Zwi, \& Lozano, 2002). Family 
functioning is impacted by violence as it disrupts the normal parent and child roles necessary for security, nurturing, learning and development (Garzon, 2017). The healthy functioning of families is important in order to produce effective members of society, illustrating how the detrimental effects of violence on family health also have farreaching effects on society (Tsitsis, 20I5). In a small rural town such as Gore, these effects are even more significant as they have the potential to impact a greater proportion of the community.

According to World Health Organization (2017) statistics, 35 percent of women worldwide have experienced family violence in their lifetime, most of which is intimate partner violence. In New Zealand, 55 percent of women report having experienced physical and/or sexual violence and psychological or emotional abuse (Ministry of Women's Affairs, 2013). Figures compiled by the New Zealand Family Violence Clearinghouse (2017) show that half of all homicides and more than half of all crime in New Zealand is related to family violence.

\section{Rural context}

Rural areas are not exempt from these trends and in fact are more at risk of family violence - 39 percent of women in rural areas experience family violence compared to 33 percent of women in urban areas (Rural Women New Zealand, 2018).

The isolation characteristic of rural areas contributes to family violence, as the large distances between homes and the infrequent accessing of health services by rural dwellers makes detection difficult (Rural Women New Zealand, 20 18). The self-described characteristics of rural culture in New Zealand are strength, hardiness and self-reliance (Bales, Winters, \& Lee, 2006). As discussed earlier, and particularly for men in Southland, this often means that males must live up to the Southern Man persona, which portrays a strong masculinity and a disdain for appearing vulnerable (Jackson et al., 2009). This concept also normalises the dominance of men over women and stigmatises seeking help as weakness, thus acting as a barrier to addressing family violence.

The family violence statistics for the town of Gore reflect this situation. Between July 2018 and April 2019, Gore Women's Refuge received 350 presentations seeking help with family violence. Māori are over-represented in these figures, with 54 percent of all presentations coming from this ethnic group (Local professional, personal communication, April 3, 2019). Physical abuse remains the most common form of violence in Gore, although psychological abuse and financial abuse are also prevalent, as is the emotional/psychological abuse of children who witness family violence (Local professional, personal communication, April II, 20 I9).

\section{Nationwide strategy}

National government-funded campaigns addressing family violence have been implemented in New Zealand. "It's not OK" was launched in 2007 as a community-driven behaviour-change campaign aimed at reducing family violence. Since the campaign's launch, more New Zealanders have been seeking help and more people believe that they can help others to change (Family Violence: It's not OK, 2019).

\section{Men as perpetrators}

The literature was reviewed to establish an evidence base for effective family violence prevention strategies aimed at men at risk of perpetration. Although not all family violence is gender-based, statistically men are more likely to be perpetrators, particularly in the case of intimate partner and sexual violence (New Zealand Family Violence Clearinghouse, 2017). Men's violence against women tends to be more severe and have more serious consequences (New Zealand Family Violence Clearinghouse, 2017). Therefore, the aim of the health promotion resources developed for this community health project was family violence prevention, with a focus on men. 


\section{Barriers to accessing help in Gore}

Although more people are beginning to discuss the issues that the Gore community faces around family violence, there are still likely to be many unreported cases and barriers preventing both victims and perpetrators from accessing help (Local professional, personal communication, April I I, 20 I9). The principle barriers to men asking for help are stigma, masculine ideology, social normalisation of violence (Local professional, personal communication, April II, 2019) and a focus on men by the criminal justice system (Donovan \& Griffiths, 20 I5). Communication with the Gore Women's Refuge representative revealed that additional barriers in the Gore community are isolation, infrequent contact with health services and minimal opportunities for healthy conversations due to long working hours (Local professional, personal communication, April II, 2019). A lack of appropriate male role models may be another barrier to men accessing family violence services. In the town, male role-models have been recruited for a "champions" campaign aimed at family violence prevention, with both non-Māori and Māori men selected. However, a rise in the number of youth gangs in Gore has seen young males looking to older gang members or leaders as their role models; these are men who often perpetuate the macho masculine ideology discussed above (Local professional, personal communication, April 12, 2019).

\section{Literature review}

A review of the literature on family violence prevention strategies (focused on men) revealed a diversity of family violence prevention programmes around the world. Viewing violence as a behaviour that could be prevented or deterred was a cornerstone of many of these strategies (Decker, Wilcox, Holliday, \& Webster, 2018). Some programmes were primarily prevention-focused and aimed at high schools or colleges (Jaime et al., 2018), while others were aimed at individuals who were at risk of, or had engaged in, violent behaviours. The interventions reported by these studies include working with couples to improve relationship skills (Kalokhe et al., 20 I9); teaching self-regulation techniques (Wistow, Kelly, \& Westmarland, 2017); stopping violence group education (Hayward, Steiner, \& Sproule, 2007); and peer support groups (Casey, Leek, Tolman, Allen, \& Carlson, 20 I7).

The following strategies were identified in the literature as effective and were taken into consideration during the development of a health promotion resource for family violence prevention in Gore:

- Positive role-modelling of non-violent behaviour (Jaime et al., 2018)

- Peer support groups (Roguski, 20I5)

- Challenging masculine ideology (Gage \& Lease, 2018)

- Focus on support and recovery rather than criminalisation and judgement of men (Donovan \& Griffiths, 2015)

- Partnership with men and emphasis on values relevant to men (Casey et al., 2017)

- Promoting resilience through teaching problem-solving, stress management and emotional regulation (Kalokhe et al., 2019; Wistow et al., 2017)

- Teaching self-regulation and self-soothing techniques (Tollefson, Webb, Shumway, Block, \& Nakamura, 2009)

- Improving communication and conflict management for couples (Kalokhe et al., 2019)

To achieve effective engagement with such prevention strategies, the barriers of masculine ideology, stigmatisation and isolation must also be addressed, particularly in a rural New Zealand community (Jackson et al., 2009; Rural Women New Zealand, 20 I8). A health promotion resource has the potential to challenge social norms and stigmas through education, language and imagery, while also raising awareness and encouraging healthy conversations (World Health Organization, 1986). 
Health promotion resources: Poster and keychain

Taking into consideration effective prevention strategies which have been utilised worldwide and those in use in New Zealand, as well as cultural and ethical considerations specific to the Gore community, a poster and keychain were developed as health promotion resources (Figures 6 and 7).

According to Boyko, Wathen and Kothari (2017), in order to effectively engage stakeholders and the wider public, violence prevention messages must be clear and consistent, derive from an evidence base and utilise evidenceinformed strategies for communication aimed at specific groups. The poster was designed to contain minimal but hard-hitting information that is consistent and taken from recent and relevant literature. The language and imagery used incorporate male and Māori values, as well as values important to the community of Gore, making it relevant to its specific target groups.

The title on the poster is designed to attract the attention of men and encourage conversation while raising awareness of family violence and its effect on the community of Gore. The body of the text challenges masculine ideology and the stigma around it. The barrier caused by isolation is targeted by emphasising the importance of seeking support and a reference to "talking it out." Use of the phrase "you are not alone" places the focus on support, making connections and challenging stigmas. The values of whānau and community are emphasised and Māori imagery is used in the form of a pair of koru, which represent origins, growth, strength and new life (Te Ahukaramū Charles Royal, 2005). The colours chosen for the poster create a simple, clear and powerful message without triggering stress in the reader (Przybyla, 2019).

A more interactive health promotion resource was designed to accompany the poster and act as a tool to promote 'time out' and self-regulating strategies. References in the literature to men "taking time out" to go for a drive (Hayward et al., 2007) led us to create a keychain with a traffic light image designed to communicate a 'stop, think, share' strategy to help de-escalate tense situations and promote support-seeking. Contact details for support services were listed on the back of the keychain.

\section{GUYS, LET'S TALK ABOUT FAMILY VIOLENCE IT IS AFFECTING OUR WHĀNAU - FAMILY — COMMUNITY}
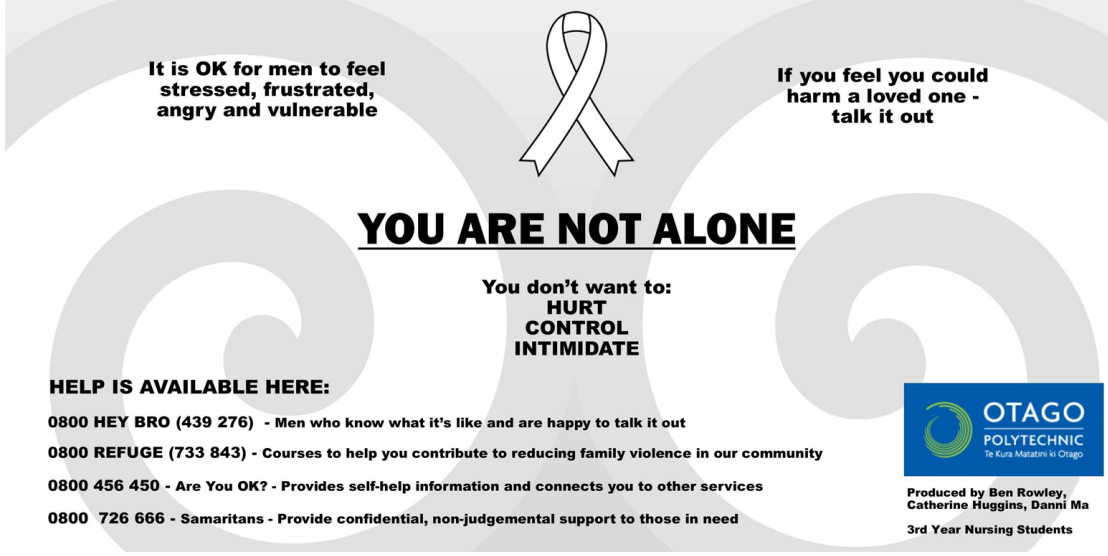

Figure 6. Family violence prevention poster.

Source: The authors. 
The support services listed on the poster and keychain are four confidential helplines which can be called by men in need of help related to family violence. 0800 HEY BRO is a 24/7 helpline staffed by men with lived experience of these issues who are available to talk with other men who are feeling at risk of harming a loved one (He Waka Tapu, 20 18). 0800 REFUGE is the national crisis number for Women's Refuge, who provide advice and support as well as educational services which promote healthy, equal relationships (National Collective of Women's Refuges Inc., 2019). The "are you OK?" phoneline is part of the "It's not OK" campaign and provides advice, support, risk assessment and safety planning to prevent offending and referral to local services (Family violence, it's not OK, personal communication, April 17, 2019). Samaritans are a charitable organisation offering 24/7 help through listening, encouraging and facilitating problem-solving for anyone requiring emotional support (Samaritans of Wellington Inc., 20 I8). Consent was obtained from these organisations for the use of their details on the health promotion resources.

\section{Impact assessment}
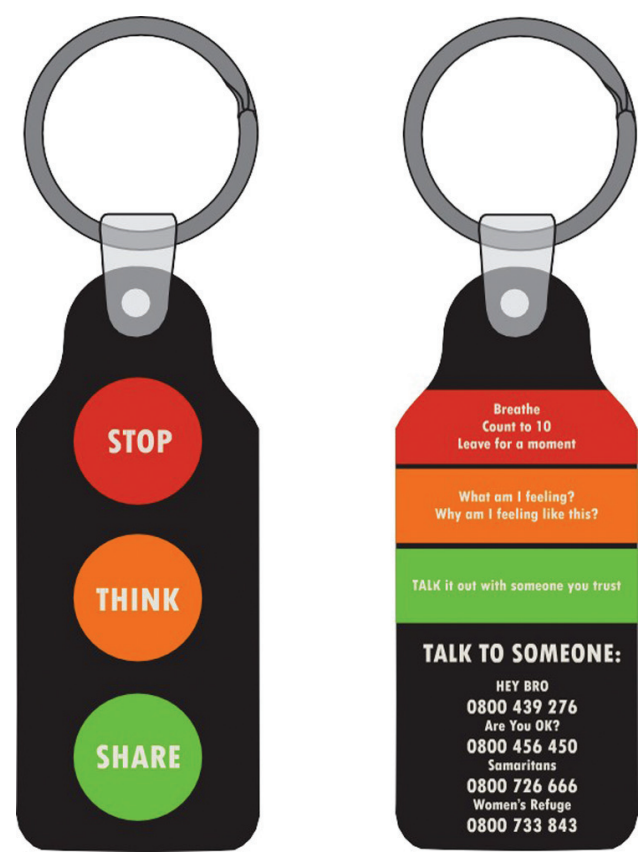

Figure 7. Family violence prevention keychain. Source:The authors.

The poster and keychain were sent to Gore Women's

Refuge and Oranga Tamariki, as they are both organisations with an interest in the project insofar as it is relevant to the health and social aspects of family violence. A follow-up discussion with these organisations revealed that the resources were well received by the community. Keychains were made available to community members visiting these two organisations and great interest was shown in them by healthcare and social service professionals, as well as by service users such as parents and whānau members. Feedback was positive regarding the messages conveyed by the resources. Importantly, representatives of Oranga Tamariki reported that they felt they provoked positive conversations about family violence.

\section{CONCLUSION}

The community assessment revealed that Gore has the capacity and resources available to address the health issues identified in this community health assessment. Values integral to the community, such as positivity, transparency and consistency, will assist in developing effective solutions. The community health project was well received by representatives of the Gore community, including the Gore District Council, which has taken into consideration the health needs identified and proposed a follow-up discussion of the Council's planned strategies to address them. It is hoped that the health promotion resources created as a result of this community project will continue to benefit the people of Gore, encouraging constructive conversations and acting as a catalyst for effective, large-scale change which would see the health and well-being of the Gore community flourish.

Correspondence to: Jean Ross, Otago Polytechnic, Dunedin, New Zealand. Email: jean.ross@op.ac.nz 


\section{REFERENCES}

Bales, R. L., Winters, C. A., \& Lee, H. J. (2006). Health needs and perceptions of rural persons. Rural nursing: Concepts, theory and practice (2nd ed.). New York: Springer Publishing.

Beattie, H. (1962). A history of Gore. Gore, New Zealand: Gore Publishing Co.

Blenkiron, P. (20I5). Cognitive behavioural therapy (CBT). Retrieved from https://www.rcpsych.ac.uk/mental-health/treatments-andwellbeing/cognitive-behavioural-therapy-(cbt)

Boyko, J. A., Wathen, C. N., \& Kothari, A. (2017). Effectively engaging stakeholders and the public in developing violence prevention messages. BMC Women's Health, 17(I), 35-35.

Casey, E. A., Leek, C., Tolman, R. M., Allen, C.T., \& Carlson, J. M. (2017). Getting men in the room: Perceptions of effective strategies to initiate men's involvement in gender-based violence prevention in a global sample. Culture, Health and Sexuality, 19(9), 979-995.

Cohlic, D., Eys, M., \& Lougheed, S. (20l I). Investigating the effectiveness of an arts-based and mindfulness-based group program for the improvement of resilience in children in need. The Journal of Child and Family Studies, 2 I (5), 833-844.

Condly, S. (2006). Resilience in children: A review of literature with implications for education. Urban Education, 4 I (3), 21 I-236.

Corrigan, P. (2004). How stigma interferes with mental health care. American Psychologist, 59(7), 6I4-625.

Decker, M. R., Wilcox, H. C., Holliday, C. N., \& Webster, D.W. (2018). An integrated public health approach to interpersonal violence and suicide prevention and response. Public Health Reports 2018, 133, 655-795.

Donovan, C., \& Griffiths, S. (2015). Domestic violence and voluntary perpetrator programmes: Engaging men in the precommencement phase. British Journal of Social Work, 45(4), I I55-1 17 I.

Downey, J.A. (2008). Recommendations for fostering educational resilience in the classroom. Preventing School Failure, 53(I), 56-64.

Dozois, D. J., Dobson, K. S., \& Rnic, K. (2019). Historical and philosophical bases of the cognitive-behavioral therapies. In K. S. Dobson \& D. J. Dozois (Eds.), Handbook of cognitive behavioural therapies (4th ed., pp. 3-3I). New York City, NY: Guilford Press.

Family Violence: It's not OK. (2019). It's not OK: About us. Retrieved from http://areyouok.org.nz/utility-pages/about-us/

Farrington, E., \& Moller, M. (2013). Relationship of vitamin D3 deficiency to depression in older adults: A systematic review of the literature from 2008-2013. Journal of Nurse Practitioners, 9(8), 506-5I 5.

Francis, K., Chapman,Y., Hoare, K., \& Birks, M. (20।3). Australia and New Zealand: Community as partner:Theory and practice in nursing. Sydney, NSW, Australia: Lippincott, Williams \& Wilkins.

Fraser, C. E., Smith, K. B., Judd, F., Humphreys, J. S., Fragar, L. J., \& Henderson, A. (2005). Farming and mental health problems and mental illness. International Journal of Social Psychiatry, 5 I (4), 340-349.

Gage, A. N., \& Lease, S. H. (20 I8). An exploration of the link between masculinity and endorsement of IPV myths in American men. Journal of Interpersonal Violence, 34(6), I I63-1 I 82.

Garzon, D. (2017). Developmental management in pediatric primary care. In C. Burns, A. Dunn, M. Brady, N. Starr, C. Blosser, \& D. Garzon (Eds.), Pediatric primary care (6th ed.). St Louis, MO: Elsevier.

Gluckman, P. (20 I7). Rethinking New Zealand's approach to mental health and mental disorder: A whole-of-government, whole-of-nation long-term committment. Retrieved from https://www.pmcsa.org.nz/wp-content/uploads/ | 7-08-| 4-Mental-health-short.pdf

Gore District Council. (2013a). District information. Retrieved from https://www.goredc.govt.nz/our-district/district-information/

Gore District Council. (20।3b). Our brand. Retrieved from https://www.goredc.govt.nz/our-district/our-brand/

Gore District Council. (2019). Welcome to the Gore District. Retrieved from https://www.gorenz.com/

Grant, D. (2008). Southland places - Eastern Southland. In Te Ara:The encyclopedia of New Zealand. Retrieved from http://www.teara. govt.nz/en/southland-places/page-4

Gregoire, A. (2002). The mental health of farmers. Occupational Medicine, 52(8), 47I-476.

Hall, N. (20I I). Give it everything you got: Resilience for young males through sport. International Journal of Men's Health, IO(I), 65-81.

Hammer, J. H., \& Vogel, D. L. (20 10). Men's help seeking for depression:The efficacy of a male-sensitive brochure about counseling. The Counseling Psychologist, 38(2), 296-313.

Harris, R., Booker, C., Caswell, M., Leitch, S., Lloyd, H., Simonsen, K., \& Willis, S. (2015). Addressing mental health and wellbeing in young people. Best Practice Journal, I (7I), 4-13.

Hayward, K. S., Steiner, S., \& Sproule, K. (2007). Women's perceptions of the impact of a domestic violence treatment program for male perpetrators. Journal of Forensic Nursing, 3(2), 77-83.

He Waka Tapu. (20I8). Services. Retrieved from https://www.hewakatapu.org.nz/services 
Health Promotion Agency. (20 I 8). Rural identity. Retrieved from https://depression.org.nz/get-better/your-identity/rural/

Jackson, S., Gee, S., \& Scherer, J. (2009). Producing and consuming masculinity: New Zealand's (Speight's) “'Southern Man." Retrieved from https://www.researchgate.net/publication/267447191_Producing_and_consuming_masculinity_New_Zealand's_ Speight's_Southern_Man

Jaime, M. C. D., McCauley, H. L., Tancredi, D. J., Decker, M. R., Silverman, J. G., \& O'Connor, B. (20 I 8). Implementing a coach-delivered dating violence prevention program with high school athletes. Prevention Science, 19(8), 1 | |3-1 122.

Johnson, J. (20I5). Participation in sports and the development of resilience in adolescents. (PhD thesis). Retrieved from https:// scholarsarchive.byu.edu/cgi/viewcontent.cgi?article=6976\&context=etd

Kalokhe, A. S., lyer, S., Katendra, T., Gadhe, K., Kolhe, A. R., Paranjape, A., .. Sahay, S. (2019). Primary prevention of intimate partner violence among recently married dyads residing in the slums of Pune, India: Development and rationale for a dyadic intervention. JMIR Research Protocols, 8(I), el I533. https://doi.org/10.2196/1 I533

Kawachi, I., \& Berkman, L. F. (200I). Social ties and mental health. Journal of Urban Health, 78(3), 458-467.

Kelly, R. (2016, November 3). Gore district on 'demographic time bomb.' Southland Times. Retrieved from https://www.stuff.co.nz/ southland-times/news/86075। 68/gore-district-on-demographic-time-bomb

Kessler, R. C., Amminger, G. P., Aguilar-Gaxiola, S., Alonso, J., Lee, S., \& Ustun, T. B. (2007). Age of onset of mental disorders: A review of recent literature. Current Opinion in Psychiatry, 20(4), 359-364.

Khanlou, N., \& Wray, R. (20|4). A whole community approach toward child and youth resilience promotion: A review of resilience literature. International Journal of Mental Health and Addiction, 12(I), 64-79.

Krug, E., Dahlberg, L. L., Mercy, J. A., Zwi, A. B., \& Lozano, R. (2002). World report on violence and health. Geneva, Switzerland: World Health Organization.

Lee, T.Y., Cheung, C. K., \& Kwong, W. M. (20I2). Resilience as a positive youth development construct: A conceptual review. The Scientific World Journal, 2012, 1-9. https://doi.org/10.1 100/2012/390450

Lown, M., Lewith, G., Simon, C., \& Peters, D. (20I5). Resilience: What is it, why do we need it and can it help us? The British Journal of General Practice, 65(639), e708-e7 I0. doi: 10.3399/bjgp I 5X687। 33

Macara, G. R. (2013). The climate and weather of Southland (NIWA science and technology series 63). Retrieved from https://www. niwa.co.nz/our-science/climate/publications/regional-climatologies/southland

Macdonald, C. (2017). Women and men - Common ground: 1999-2Ist century. In Te Ara: The encyclopedia of New Zealand. Retrieved from https://teara.govt.nz/en/ephemera/29266/southern-man

Mackenzie, C. S., Gekoski,W. L., \& Knox, V. J. (2007). Age, gender, and the underutilization of mental health services:The influence of help-seeking attitudes. Aging \& Mental Health, 10(6), 574-582.

Ministry of Health. (2016). Family violence assessment and intervention guideline: Child abuse and intimate partner violence (2nd ed.). Wellington, New Zealand: Ministry of Health.

Ministry of Justice. (2019). Reducing family and sexual violence. Retrieved from https://www.justice.govt.nz/justice-sector-policy/keyinitiatives/reducing-family-and-sexual-violence/

Ministry of Women's Affairs. (20I3). Current thinking on primary prevention of violence against women. Wellington, New Zealand: Ministry of Women's Affairs.

Murphey, D., Barry, M., \&Vaughn, B. (2013). Positive mental health: Resilience. Retrieved from https://www.childtrends.org/wp-content/ uploads/2013/03/Child_Trends-2013_II_OI_AHH_Resilience.pdf

National Collective of Women's Refuges Inc. (2019). What we do. Retrieved from https://womensrefuge.org.nz/what-we-do/

New Zealand Family Violence Clearinghouse. (2017). Data summaries 20 I : Snapshot. Auckland, New Zealand: New Zealand Family Violence Clearinghouse, University of Auckland.

New Zealand Health Survey. (20 I 8). Regions: Southern and New Zealand. Retrieved from https://minhealthnz.shinyapps.io/nz-healthsurvey-20 |4-|7-regional-update/_w_09423199/_w_8959c049/_w_33f48de4/_w_f49964cl/\#!/compare-indicators

Newman, T. (2018, April 30). Gore sets sights on new growth plan. Southland Times. Retrieved from https://www.stuff.co.nz/ southland-times/news/I 03 | 65225/gore-sets-sights-on-new-growth-plan

Nicol-Williams, K. (2018, June 2I). It's making everyone grumpy: Low sunshine hours taking toll on New Zealand. One News. Retrieved from https://www.tvnz.co.nz/one-news/new-zealand/its-making-everyone-grumpy-low-sunshine-hours-taking-tollnew-zealanders

Noble, T., \& McGrath, H. (2005). Emotional growth: Helping children and families 'bounce back'. Australian Family Physician, 34(9), 749-752.

Patterson, E. (2007). Health promotion. In W. St John \& H. Keleher (Eds.), Community nursing practice:Theory, skills and issues. Crows Nest, NSW, Australia: Allen \& Unwin. 
Przybyla, D. (2019). The psychology and meaning of colors. Retrieved from https://www.colorpsychology.org/

Roguski, M. (20I5). 'It's not OK' campaign community evaluation project. Wellington, New Zealand: Ministry of Social Development.

Roy, P., Tremblay, G., Oliffe, J. L., Jbilou, J., \& Robertson, S. (2013). Male farmers with mental health disorders: A scoping review. Australian Journal of Rural Health, 21 ( I), 3-7.

Rural Women New Zealand. (20/8). We are helping build safer communities. Retrieved from https://www.ruralwomen.org.nz/ ok2help.html

Samaritans of Wellington Inc. (20 I). Welcome to Samaritans. Retrieved from http://www.samaritans.org.nz/

Southern District Health Board. (2016). Youth primary mental health services - Brief intervention: Review of service configuration and related issues. Retrieved from https://www.southerndhb.govt.nz/files/20003_20 I 705 I 2 I0 | 42 | - |49454086 I.pdf

Statistics New Zealand. (2013). 2013 census quickstats about a place: Gore district. Retrieved from http://archive.stats.govt. nz/Census/20 I 3-census/profile-and-summary-reports/quickstats-about-a-place.aspx?request_value $=|5| 52 \&$ parent id $=|5| \mid 2 \&$ tabname $=\#|5| 52$

Steiner, H., McQuivey, R. W., Pavelski, R., Pitts, T., \& Kraemer, H. (2000). Adolescents and sports: Risk or benefit? Clinical Pediatrics, 39(3), $|6|-166$.

Strate, L. (1992). Beer commercials: A manual on masculinity. In S. Craig (Ed.), Men, masculinity, and the media. Thousand Oaks, CA: Sage Publications.

Te Ahukaramū Charles Royal. (2005). Maori creation traditions: Common threads in creation stories. In Te Ara: The encyclopedia of New Zealand. Retrieved from https://teara.govt.nz/en/photograph/2422/the-koru

The Adolescent Health Research Group. (2013). The health and wellbeing of Maori New Zealand secondary school students in 2012 : Te ara whakapiki taitamariki:Youth'I 2 Auckland, New Zealand:The University of Auckland.

Tollefson, D. R., Webb, K., Shumway, D., Block, S. H., \& Nakamura,Y. (2009). A mind-body approach to domestic violence perpetrator treatment: Program overview and preliminary outcomes. Journal of Aggression, Maltreatment \& Trauma, | 8, | 7-45.

Tsitsis, N. (20I5). Social aspects of family protection. Health Science Journal, 9(2), I-5.

Wickrama, K. A. S., Conger, R. D., \& Abraham, T.W. (2005). Early adversity and later health: The intergenerational transmission of adversity through mental disorder and physical illness. The Journals of Gerontology: Series B, 60(2), I25-129.

Wistow, R., Kelly, L., \& Westmarland, N. (2017). 'Time out': A strategy for reducing men's violence against women in relationships? Violence Against Women, 23(6), 730-748.

World Health Organization. (1986). Ottawa charter for health promotion. Retrieved from http://www.who.int/healthpromotion/ conferences/previous/ottawa/en/

World Health Organization. (2017). Violence against women. Retrieved from https://www.who.int/news-room/fact-sheets/detail/ violence-against-women

Zarobe, L., \& Bungay, H. (2017). The role of arts activities in developing resilience and mental wellbeing in children and young people: A rapid review of the literature. Perspectives in Public Health, 137(6), 337-347. 